\title{
PODER, RANGO Y ECONOMÍA DE LAS AUTORIDADES Y HOMBRES PRINÇIPALES DE LA TAHA DE VERA EN EL REINO NAZARÍ (S. XV)
}

\author{
POWER, RANK AND ECONOMY OF THE AUTHORITIES AND \\ PRINCELY MEN OF THE TAHA OF VERA IN THE NASRID KINGDOM \\ (15TH CENTURY)
}

\author{
السلطة والمكانة والاقتصاد لدى السلطان والأعيان في مدينة بيرة بالمملكة النصرية \\ María Arcas Campoy* \\ Universidad de La Laguna
}

BIBLID [1133-8571] 28 (2021) 103.1-14

Recibido: 24/05/21 Aceptado: 28/06/21

Resumen: El análisis y estudio del rango social y las cotas de poder de los representantes de la autoridad (sulțān) del soberano nazarí en Vera y su territorio en la segunda mitad el siglo XV, además de aportar valiosos datos sobre varios aspectos relacionados con sus cargos (nombramiento, competencias, jurisdicción territorial, etc.), abren la posibilidad de formular algunas hipótesis respecto a su posición económica y patrimonio. Asimismo, dichas hipótesis son aplicables a las personas que gozaron de prestigio y respeto, consideradas «hombres principales». Este trabajo se basa en documentos legales y oficiales del siglo XVI cuyo contenido se retrotrae a los últimos tiempos del reino nazarí en la taha de Vera.

Palabras clave: Taha de Vera. Autoridades. Hombres principales. Poder. Categoría. Economía.

\begin{abstract}
Analysis and study of the social rank and echelons of power of those who represented the authority (sultāan) of the Nasrid king in Vera and surrounding area in the second half of the 15th century not only provide valuable data on various aspects of their positions (appointment, powers, territorial jurisdiction, etc.) but also the opportunity to formulate several hypotheses about their economic status and wealth. Such hypotheses are equally applicable to individuals who enjoyed great prestige and respect, and who were considered "leading men". This paper is based on legal and official 16th-century documents, the content of which traces back to the final stages of the Nasrid kingdom in the Taha of Vera.
\end{abstract}

Keywords: Taha of Vera. Authorities. Leading men. Power. Category. Economy.

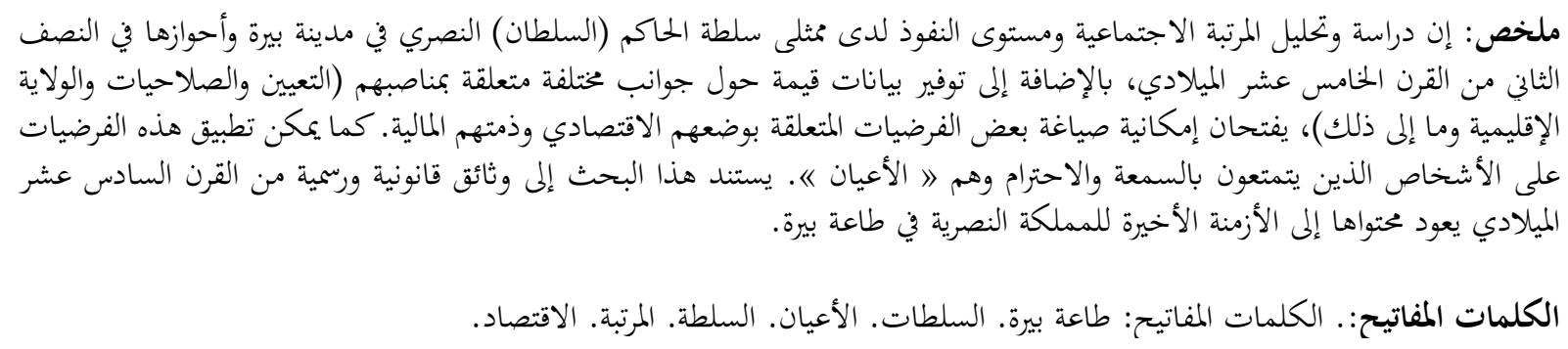

* Email: marcascamp@gmail.com. ORCID: 0000-0003-4553-165X. 


\section{Introducción}

La mayor parte de la información sobre este trabajo procede de las Probanzas del pleito entre Lorca y Vera (años 1511-1559) ${ }^{(1)}$ por la delimitación de sus términos, que contiene las declaraciones de numerosos testigos de ambas partes del litigio. Los testigos de Vera defendían los derechos jurisdiccionales sobre Huércal y Overa desde tiempo de moros mientras que los de Lorca argüían que la administración y gobierno de ambas villas dependía de personas nombradas directamente por el rey granadino. También existen importantes datos en otros documentos entre los que se encuentran varias cartas bermejas romanceadas, misivas oficiales y escritos notariales del siglo XVI (Arcas Campoy, 2015: 8-17) que, al igual que las Probanzas, se conservan en el Archivo Municipal de Lorca.

La ciudad de Vera, el núcleo urbano más importante del confín oriental granadino, gozaba de la consideración de capital administrativa del distrito o taha $\left(t a^{\varsigma} a\right)^{(2)}$ de su nombre, si bien este hecho no implicaba dominio alguno sobre sus aldeas ya que éstas tenían su alguacil y alcaide puesto por el rey moro y no por ninguna çibdad. Así consta en una de las preguntas formuladas por la parte de Lorca (Jiménez Alcázar 1996: 24). Igualmente, el testigo por la parte de Vera ${ }^{(3)}$, Gabriel Aladuli (PV, 1511, 1v), confirma su categoría como ciudad principal del distrito, pero discrepa de la última parte alegando que las villas de Guercal y Overa son de la taha de Vera, que quiere decir de la tierra de Vera.

Esta ciudad fronteriza, como cabeza de una taha, tenía la categoría de capital de su distrito y en ella residían los representantes de la autoridad del emir granadino. Vera era, por lo tanto, el lugar en el que se ubicaba la delegación de la autoridad (sulțān) suprema ejercida en todo el territorio bajo su jurisdicción por personas con cargos, categorías y competencias diferentes, relacionados principalmente con el gobierno, defensa y administración de la justicia (Arcas Campoy 2006: 281-293). Tanto en la ciudad como en todo el territorio de su jurisdicción, además de las autoridades mencionadas, vivía el resto de los ciudadanos entre los que destacaban varias personas que, por su prestigio social, gozaban de la consideración de hombres prinçipales moros (Juan de Narvaez PV, 1518, 52r) o de hombres viejos prinçipales (Alonsso Venzada, PV, 1518, $70 \mathrm{v})^{(4)}$.

\section{Gobierno y defensa}

Los testigos de ambas partes del Pleito aportan abundantes y variados datos sobre las personas que ejercieron como gobernantes y jefes militares de Vera en la segunda mitad del siglo XV. Es conveniente tener en cuenta que estos testigos, en su inmensa mayoría cristianos nuevos ${ }^{(5)}$, longevos, con onomásticas cristianas y castellanas, seguían siendo arabófonos, excepto dos «aljamiados» ${ }^{(6)}$, que también podían expresarse en romance, lo que significa que sus declaraciones

(1) Archivo Municipal de Lorca, Sala II, 217 bis. Dos volúmenes: Parte de Vera y Parte de Lorca. Arcas Campoy ha realizado varios trabajos basados principalmente en el citado pleito a partir de «Noticias sobre el cadiazgo» (1992).

(2) Corriente (1999), Diccionario de Arabismos, p. 448, taha: 'distrito' < del andalusí táa $a<$ árabe clásico țā $a$, 'obediencia'. Sobre el concepto de țā̧a véase Arié (1992), El reino nașrí de Granada), pp. 117-118, y Jiménez Alcázar, Huércal y Overa (1996), pp. 23-31.

(3) En adelante cito PV $=$ Parte de Vera y PL = Parte de Lorca, año y $\mathrm{n}^{\circ}$ de folio.

(4) Viguera (2000), «El soberano», p. 355, hace referencia a hombres 'honrados', 'viejos' o 'jeques' que formaban parte del Consejo local.

(5) No era infrecuente llamar a testificar a los cristianos nuevos en los pleitos castellanos como indican Abad Merino y Jiménez Alcázar (2001), «Item si sabe», pp. 29-30.

(6) Corriente (1999), Diccionario de Arabismos, p. 179, 'aljamía' < del andalusí 'aŷamiyya < árabe clásico ‘aŷamiyyah, 'lengua bárbara'. Epalza (1992), Los moriscos antes y después de la expulsión, p. 116, afirma, refiriéndose a los aljamiados, que la población originaria de Granada era monolingüe arabohablante, aunque los había que conocían el castellano para entenderse en tratos. 
fueron traducidas y escritas en castellano por intérpretes y escribanos ${ }^{(7)}$ con las consiguientes dificultades para adaptar los términos árabes, oídos de viva voz, a la grafía latina. A ello hay que añadir el trasvase semántico de muchos términos de una lengua a otra, del árabe al castellano, con significados más o menos equivalentes en ambas sociedades. Es el caso de varias voces que designan cargos de autoridad en Vera.

Los testigos se refieren a quienes ejercían dichos cargos como alcaides y caudillos. Aunque sus étimos son distintos ${ }^{(8)}$, el significado de ambos términos es bastante aproximado en los contextos sociopolíticos castellano y nazarí de la época: jefe político y militar, gobernador. Entre la nómina de titulares de la alcaidía de Vera, mencionados como caudillos y/o alcaides por los testigos de la parte de Vera en los años indicados, destacan Adanayar, Aynen (Ayne, El Xa Aynin, Xe Ayne,) Abdalivar (Abdilbar, Avdalibar, Abilbar), Venalaxar (Abenhalaxar), Audaladin Buzete (Buzet), Abulhaya (Abulhayar), Famete Alcadi, Bohedar, El Je Abulxuher y Hichi (Yay ¿Yahya?) El Nayar. De este último indica Diego El Chilichi (PV, 1550, 164r, 165r) que era padre de Don Alonsso Vanegas y, según refiere Fernando de Guzman (PV, 1559, 272v) con mayor precisión, era el aguelo de don Pedro Banegas, que llamavan Yay Nayar e tubo un hijo que es el padre del dicho Don Pedro Banegas, que llamavan Ali El Nayar ${ }^{(9)}$.

Por el contrario, los testigos de la parte de Lorca, que defendía la independencia jurisdiccional de Huércal y Overa, se refieren casi exclusivamente a los alcaides de ambas villas que, como afirma Anton de Tijola (PL, 1534, 91r), eran puestos por el rrei moro de Granada y no por la ciudad de Vera. Cabe mencionar, entre otros, los nombres de los alcaides Muley Ali, el Moratali y Aben Feçin, El Moratali, Rreduan, Hamar Alzubari, Zuliante Alaravi, Aben Farrax (alcaide de Huércal y Vera), Muley Falis, Albuaça, Abernerramy, Hamete Hazla (Alhazli) y Al Haje.

A pesar de las diferencias de intereses de las partes en litigio, las declaraciones de los testigos aportan valiosos datos sobre el rango y poder de los alcaides y de otros cargos de menor categoría y dependientes o relacionados de algún modo con ellos.

El alcaide de Vera representaba la autoridad del rey granadino en la ciudad y su distrito con competencias militares, administrativas y judiciales en materia penal. De él dependía la defensa de la frontera con Lorca y el abastecimiento y reparación de sus fortalezas (principalmente de Huércal y Overa), la recepción de impuestos por la entrada de ganados foráneos ${ }^{(10)}$, los canjes de prisioneros en tiempos de paces, la detención de delincuentes, el mantenimiento del orden público y la ejecución de penas a su arbitrio o subsidiarias de las dictadas por el cadí. Entre los numerosos testimonios de las mencionadas competencias del alcaide de Vera destacan los siguientes:

a) Bernardo Elbudut (PV. 1512, 28v):

vido este testigo que en la d(ic)ha çiudad de Vera estava un caudillo en tiempo de moros que se deçía Venalaxar, que quando entravan algunos ganados sin liçençia en los d(ic)hos términos, que los prendava y les tomava el taybix y los derechos y se los hazía pagar y que este testigo ansí lo bido y lo oyó dezir a sus mayores y anzianos.

b) Juan de Narvaez ( PV. 1518, 51v-52r):

estubo con el dicho caudillo Abdilbar Buzet que fue como dicho a, puede aver treinta y cinco

(7) La labor de estos escribanos anónimos coincide con la de los intérpretes "latentes" descrita por Abad Merino (2005-2006), «Intérpretes latentes», pp. 17

(8) Caudillo, 'cabecilla', 'jefe de un grupo armado' deriva del latín tardío capitellum, diminutivo del latín clásico caput, en tanto que alcaide, Corriente (1999), Diccionario de Arabismos, p. 130, procede del andalusí alqáy $(i) d$, 'conductor de tropas' < árabe clásico $a l-q \bar{a}$ 'id. Sobre los alcaides en ciudades menores, castillos y zonas fronterizas del reino nazarí, remito a Viguera «El soberano» (2000), p. 352.

(9) Sobre El Nayar remito a Espinar y Grima (1993), «Un personaje almeriense en las crónicas musulmanas y cristianas», pp. 89-124, y «Testamento y muerte de Don Pedro de Granada», pp. 125-149.

(10) Arcas Campoy (2014), «Sobre algunas funciones extraordinarias asumidas por el cadí de Vera», pp. 69-73, aborda la cuestión del impuesto del taybix en esta zona. 
o quarenta años y bivió con él por tiempo de un año el dicho tiempo beya y vido que desde Vera llebaba bastimentos a la dicha Guercal y Overa y traya de allá los diezmos del pan que coxían los de los dichos lugares y por esta caussa dixo que save que los dichos lugares estavan asentados en los términos de la dicha çiudad y veya y vido que los términos donde los dichos lugares estavan y los dichos lugares heran avidos y tenidos por términos y lugares de la dicha çiudad de Vera los mandava el dicho caudillo y ponía justiçia en ellos en el dicho tiempo que en la dicha çiudad estuvo y que al dicho caudillo, cadis, y hombres prinçipales moros de la dicha çiudad de Vera les oya y oyó deçir al dicho tiempo que desde que la tierra hera de moros los dichos lugares avían sido y heran de moros los dichos lugares avían sido $y$ heran de la dicha çiudad de Vera y que estaban en su término y tierra de la dicha çiudad de Vera.

c) Fernando Alforayad (PV, 1518, 82r-82v):

Estando este testigo en la d(ic)ha çiudad de Vera biviendo con el dicho caudillo Ayne que de suso dicho tiene, en tiempo de pazes entre los de Lorca y Vera vido que çiertos xpi(sti)anos de Lorca vinieron a se quexar y hazer saver al dicho caudillo Ayne como ziertos moros avían hurtado dos cristianos de Lorca y que dexavan el rrastro en la fuente La Higuera y el dicho caudillo vido y supo que fiço la pesquissa y halló los dichos dos cristianos y el dicho alcayde y otros cavalleros moros y este testigo con ellos fueron a la dicha fuente La Higuera y vido que alli el dicho caudillo entregó los dichos xpi(sti)anos a ziertos cavalleros de Lorca.

Queda claro que los testigos de Vera, aunque mencionan el nombre de varios alcaides de Huércal y Overa, siempre lo hacen insistiendo en que habían sido nombrados por la autoridad de la principal ciudad de la taha. Un buen ejemplo se encuentra en la declaración de Francisco El Mozaqui El Ballestero (PV, 1518, 108v) al afirmar que en el dicho tiempo de moros bio y conoçio ser alcaydes en la dicha villa de Guercal puestos por la d(ic)ha çiudad de Vera a los alcaydes y personas siguientes El Bexari y Famete Guaçina y Alhedin y Alpanox y a Mafoma Alguaçir y Alvic/çar qu(e) estavan puestos por Famete Alcadi, que hera en el dicho tiempo alcayde y caudillo de la dicha çiudad de Vera.

Sin embargo, los testigos de la parte de Lorca mantienen que ambas villas cobraban los derechos de pastos, como indica Juan Baladerrei (PL, 1511, 7r) al declarar que cuarenta años atrás fue con ganado al campo de Huércal y tuvo que entregar al alcaide de este lugar, llamado Muley Ali, dos cabritos y un carnero de derecho de herbaje- y que sus alcaides eran nombrados directamente de mano del rei de Granada, hecho corroborado también por una pieza incorporada al pleito en 1551 que contiene la versión romanceada de nueve cédulas reales o cartas bermejas remitidas entre los años 1409 y $1488^{(11)}$.

Igualmente importantes son las referencias a otros cargos de menor categoría porque aportan información sobre la autoridad y poder de los alcaides, principalmente los de Vera. Numerosos testimonios aluden a quienes desempeñaron el cargo de alguacil (wazìr) como subalternos o colaboradores del alcaide y/o del cadí. Los testigos de la parte de Vera afirman que los alguaciles de Huércal y Overa dependían de la autoridad de la ciudad principal en todos los aspectos, desde el cobro de tasas por herbaje hasta el abastecimiento de sus habitantes en tiempo de guerra. Valga como ejemplo el testimonio de Anton de Raya (PV, 1534, 133v-134r), caballero del alcaide Xe Shined durante cuatro años, quien relata que bido que muchas vezes venían a casa del d(ic)ho

(11) Estas cartas romanceadas, conservadas en el Archivo Municipal de Lorca, han sido editadas y estudiadas por Espinar y Grima (1988), «Estudios de algunas cartas de los reyes nazaríes dirigidas a los habitantes de Huércal», pp. 39-57, y por Fontenla (1992), «Nueve cédulas reales de los últimos sultanes nazaríes (Primera parte)», pp. 195-212, y (1993) «Nueve cédulas reales de los últimos sultanes nazaríes (Segunda parte)», pp. 17-30. Arcas Campoy (2015), «Documentos legales», pp. 13-16, ofrece un comentario sobre las mencionadas cartas bermejas y también alude a los nombramientos de alcaides de Huércal en otras misivas de los sultanes nazaríes. Viguera (2000) Capítulo II: 
alcayde de Vera, amo deste testigo, los principales veçinos y alguaçiles de los d(ic)hos lugares de Guercal y Overa a pedir just(ici)a y socorro y bastimento porque hera tiempo de guerra e todas las otras cossas de que tenían nezesidad al d(ic)ho alcayde, que hera just(ici)a mayor como caveça que hera de la d(ic)ha zuidad de Vera y el d(ic)ho alcayde de la d(ic)ha zuidad de Bera les dava bastim(en)to y socorro de lo que avían menester.

Además, los alguaciles como lugartenientes de los alcaides y cadíes en los núcleos de población dependientes de Vera, estaban facultados para ejecutar mandamientos civiles y criminales y prender a los delincuentes. Sin embargo, los escasos testimonios referidos a la figura de un alguacil de Vera resultan un tanto confusos ya que parecen aludir a la principal autoridad, al menos en el caso de Hamete El Cadi, mencionádolo indistintamente como alcaide, cadí, caudillo, alguacil, gobernador y hombre principal, tal vez porque desempeñara todos estos cargos simuláneamente o en distintos momentos ${ }^{(12)}$.

También colaboraba con la autoridad veratense el amojarife (mušrif). Su misión era el cobro del diezmo ( ${ }^{\wedge} u s ̌ r$ ) de Vera y sus términos comunes y baldios según varios testimonios, entre ellos el de Fernando Alforayad (PV, 1518, 96r), quien afirma que, estando al servicio del caudillo Ayne, vido que todos los diezmos de pan y paniço y otras semillas que se sembravan y coxían en los términos de la dicha çiudad de Vera haçia los dichos límites se pagavan y pagaron en la dicha çiudad de Vera a los almoxarifes que la dicha çiudad ponía.

Entre otros colaboradores de la máxima autoridad de Vera figuraban los adalides (dalīl) que se encargaban de acciones concretas en la frontera e incluso en territorio enemigo y que solían pertenecer a familias conocidas, como el caso de los Abenzada ${ }^{(13)}$. Según Jeronimo Omar (PV, $1518,74 \mathrm{r}$ ), un adalid, que se deçía Abenzada, fue enviado por el caudillo Aynen a rescatar a dos moros de Mojácar que habían sido apresados por los de Lorca en tiempo de paces. Y es que esta zona fronteriza, aunque con menor intensidad bélica desde mediados del siglo $\mathrm{XV}$, continuó siendo escenario de conflictos «celadas, cautiverios, algunos robos y hurtos, con cabalgadas muy esporádicas hasta el inicio de las hostilidades definitivas en 1482» (Jiménez Alcázar 1996: 20). También caben ser destacadas las necesarias y frecuentes actuaciones de los alfaqueques y ejeas (axeas, exeas o egeas, según los escribanos) ${ }^{(14)}$ en los procesos de rescate, canje de cautivos, traducción $^{(15)}$ e intermediación entre las autoridades de Lorca y Vera ${ }^{(16)}$.

Iguamente mercen ser mencionados los caballeros, los escuderos y los criados a sueldo de los alcaides, que actuaban como ejecutores de sus órdenes. Es el caso, entre otros, de los testigos Juan de Narvaez (PV, 1518, 51r-51v), escudero del caudillo Abdilbar Buzete, que fue a los dichos lugares de Guercal y Overa a llevar desde Vera bastimentos a los dichos lugares, de Jeronimo Omar (PV, 1518, 58v-59r), también escudero de mencionado Aynen, al que acompañaba asiduamente, o de Anton de Raya (PV, 1534, 134r), caballero al servicio del alcaide Xe Shined. Igualmente, los criados en algunas ocasiones se ocupaban de llevar a Vera el ganado requisado por haber entrado sin licencia en el campo de Huércal. Juan Canastón (PV, 1512, 32r-32v) dice al

(12) Viguera (2000), «El soberano», pp. 352-353, en el estudio dedicado a la figura del alguacil en el reino nazarí indica que en ocasiones este título y el de alcaide se aplicaban simultáneamente.

(13) Jiménez Alcázar (1996), Huércal y Overa, p. 21, refiere que fue celebrada la muerte de Abenzada El Bizco en 1482 y menciona a otros adalides en esta zona: Gaitán, Gafal, vecino de Cuevas, Aborroy, de Zurgena, Yuçef Algazí y Garzán Gazí, de Vera.

(14) Corriente (1999), Diccionario de arabismos, p. 156, alfaqueque, 'redentor de cautivos', del andalusí alfakkák < clásico fakkāk; y p. 304, exea, 'explorador, guía', del andalusí $i \check{s ̌ s} i^{i} a<$ clásico ši $i^{\zeta} a$,'compañía'.

(15) Abad Merino (2003), «Exeas y alfaqueques», pp. 35-50, analiza la labor como intérpretes de estos personajes de frontera.

(16) García Antón (1987), «Cautiverios, canjes y rescates», pp. 547-559, ofrece un documentado estudio sobre ejeas, alfaqueques y otas figuras afines que desempeñaron una importante y necesaria función en las relaciones fronterizas de la zona. Sobre este tema véase también Martínez Almira (2003), «A propósito del rescate de cautivos», pp. 457- 496. 
respecto que el alcaide Aben Halaxar envio desde Vera çiertos mozos criados suyos a traer del dicho campo de Guercal un hato de ganado ovejuno prendado.

Alonso de Mendoza (PV, 1518, 82v-83r, 88v) da a entender que él también fue su escudero cuando afirma que vivió con el caudillo Aynen y otros 12 escuderos moros. Asimismo cabe señalar que los criados, en algunas ocasiones, se ocupaban de ejecutar las órdenes del alcaide en las actuaciones de su competencia. Así lo hace constar Cristobal Lopez Almimi (PV, 1550, 198r$198 v)$ al mencionar que envió a sus criados a echar ganados de los pastos de Huércal.

Valga como ejemplo del poder de estas autoridades locales la figura del alcaide Aynen ('Inān) cuyo nombre, con algunas variantes gráficas según los escribanos, aparece citado en numerosas ocasiones en las declaraciones de once testigos del pleito. Seis de ellos lo mencionan como Ayne (Gomez Fajardo, Pedro El Antequeyre, Jeronimo Omar, Fernando Alforayad, Alonso de Mendoza, Garcia Alesponi), tres, como Aynen (Juan de Velasco, Cristobal Lopez Almimi, Gonzalo Yaçid), uno, como Ynen (Diego El Totrizi) y otro, como Aynin (Diego de Elague, variante en la que se aprecia la imāla del andalusí granadino.

Aynen, como todos los alcaides de Vera, fue nombrado por el monarca granadino para ejercer dicho cargo. Así consta en el testimonio de Gonzalo Yaçid (PV, 1550, 204v-205r) quien afirma que el mencionado alcaide tenia provission del rrey moro que aquella sazon rreynava que se llamava Muley Abuhazen. Este dato, además de indicar el nombre del monarca -Abū 1-Hasan 'Alī (888-8907/1464-1482 y 869-88/1482-1485) - del que recibió el nombramiento, permite una aproximación cronológica aproximada del mandato de este personaje cuya residencia oficial, según Pedro El Antequeire (PV, 1518, 56r) era la alcaçaba de la dicha de la dicha çiudad de $\operatorname{Vera}^{(17)}$. La mencionada alcazaba, ubicada en la sierra del Espiritu Santo, estaba protegida por un circuito que rodeaba la falda de la montaña ${ }^{(18)}$. La ciudad, que se hallaba situada en la parte llana, y las edificaciones del cerro fueron destruídas por un gran terremoto en $1518^{(19)}$, que determinó la construcción de la nuevaVera en el sitio actual.

La jurisdicción territorial del alcaide Aynen, siempre según los testigos de la parte de Vera, incluía varias villas y aldeas entre las que se encontraban Huércal y Overa. Y, desde luego, como máximo representante del rey de Granada en Vera y su territorio, tenía competencias en materia civil, militar y penal.

\section{Administración de la justicia}

El cadí $(q \bar{a} d \bar{\imath})$ era el representante de la autoridad del soberano en lo que en la administración de la justicia se refiere, sin olvidar que también podía reservarse el derecho de actuar libremente en asuntos criminales atribuidos a los delegados del poder ejecutivo. Los candidatos al ejercicio de la judicatura $\left(q a d \bar{a}^{\prime}\right)$ en el occidente islámico debían reunir determinados requisitos a los que se refieren, con algunas diferencias, varios juristas malikíes.

Se puede afirmar que, dado el carácter individual de su título, el cadí en la Granada nazarí ${ }^{(20)}$

(17) Arié (1992), El reino nașrí de Granada, pp. 117-188, refiere que, en el reino nazarí, ya desde el siglo XIV, el gobernador residía en la alcazaba de la ciudad principal del distrito.

(18) Del Cerro Bex (1980), «Un padrón de los mudéjares», p. 63, y Jiménez Alcázar (1994), El libro del repartimiento de Vera (1994), p. 18, recoge la referencia de Del Cerro Bex y amplía la información sobre la alcazaba en los años posteriores a la conquista y sobre las obras de restauración de las que fue objeto hasta el devastador terremoto de 1518 y que supuso la ubicación de la actual ciudad de Vera. Véase el extenso estudio arquelógico de Cara Barrionuevo y Ortiz Soler (2019), «Aproximación al conocimiento de la Vera medieval», pp. 71-114.

(19) El Ayuntamiento de Vera dedicó varias actividades en conmemoración del mencionado terremoto, entre ellas, la publicación coordinada por Luque de Haro y Caparrós Perales (2019), La tierra de Vera. Nuevas contribuciones sobre la historia de un territorio de frontera.

(20) Calero Secall (2000), «La justicia», pp. 35-427, en su documentado estudio sobre el cadiazgo en el reino nazarí, trata de los cadíes locales, sustitutos e itenerantes (pp. 381-385). 
era el pilar único de las causas judiciales pertenecientes a su jurisdicción, si bien contaba con la necesaria colaboración de otros jueces en los que delegaba algunas de sus funciones. En lo que se refire al contexto temporal y espacial que nos ocupa (Arcas Campoy, 1999, «Cadíes y alcaides»), los testimonios recogidos en las mencionadas Probanzas contienen importantes datos sobre los cadíes de Vera: nombres, sede judicial, nombramientos, competencias, jueces delegados y otros colaboradores del cadí.

Entre los escasos nombres de cadíes de Vera mecionados por los testigos figuran los de Alcadi el Biejo, Mahomad / Mahomat, Alcadi (¿el Biejo?), Hamete Elcadi, El Xehera, El Alçir y Habraen Yaçid / Habraen Aben Yaçid). Estos y otros cadíes, cuyos nombres se desconocen, ejercieron su cargo en la sede judicial de Vera y su autoridad se extendía a todas las aldeas y villas de su jurisdicción, según los testigos de la parte veratense porque los de Lorca, por el contario, alegaban que cada población tenían su propio juez. No obstante la manifiesta oposición de las partes en litigio, las declaraciones de los testigos también aportan interesantes datos sobre el nombramiento de los titulares del cadiazgo. Tanto unos como otros indican que los cadíes eran nombrados directamente por rey granadino, los de Vera alegando que su cadí era el único titular de su sede y villas de su jurisdicción, como refiere Gonzalo Yaçid (PV, 1550, fol. 204v) respecto a su padre, el cadí Habraen Yaçid ${ }^{(21)}$. Otros testigos, en cambio, afirman que el nombramiento les venia de mano del cadí supremo ( $q \bar{a} d \bar{l} \bar{l}$ al-ŷam $\bar{a}^{\varsigma} a$ ) residente en Granada, que era como padre sancto, sin embargo, no hay que apreciar en ello una contradición ya que las actuaciones de quienes ostentaban esta dignidad debían estar supervisadas por el soberano.

En cuanto a las competencias del cadí de Vera cabe destacar que podían ser ordinarias y extraordinarias (Arcas Campoy 2014: 67-76). Las primeras incluían las actuaciones propias de su cargo, tanto las de carácter judicial (causas civiles y penales, principalmente las primeras) como extrajudicial, asumidas estas de forma habitual, accidental o motivadas por los acontecimientos y entre las que figuraban el cobro del impuesto del taybix de los ganados que entraban a pactar en el campo de Huércal, la recepción del quinto (jums) de las cabalgadas en tierra enemiga y el abastecimiento y reparación de las fortalezas de Huércal y Overa.

Al igual que los alcaides y caudillos, los cadíes de Vera contaban con la colaboración de otras personas de menor rango en el desempeño de sus funciones. Los testigos del pleito aluden a las figuras del escribano o secretario $(k \bar{a} t i b)$ y del juez delegado $\left(n \bar{a}^{\prime} i b\right)$. Respecto a los segundos, los de la parte de Vera mantienen que el cadí de la sede judicial mandaba delegados a Huércal y Overa a resolver asuntos civiles frente a las declaraciones de los testigos por Lorca que aluden a la presencia de ciertos cadíes que, nombrados por el monarca granadino y su cadí supremo, ejercían su cargo con competencias limitadas y de forma itinerante.

También es mencionada la figura del alfaquí (faqīh) en ambas partes del pleito como persona instruida en el derecho y vinculada a la administración de justicia e incluso refiriéndose a los propios cadíes. Así consta en una pregunta formulada por la parte de Lorca (año 1558, 234r) pidiendo a los testigos que declaren si saben que los cadis heran alfaquíes y hombres sabios en su lei y ellos declaraban las dudas de su ley. En el mismo sentido se pronuncia el mencionado Gonzalo Yaçid (PV, 1550, fol. 160v-161r) indicando que su padre, Habraen Aben Yaçid, era cadi en la çiu(dad) de Vera y alfaqui y tiniendo estos cargos este testigo estuvo con el d(ic)ho su padre en la çiudad de Vera tiempo de dos años poco mas o menos.

\section{Rango y poder económico}

Lo expuesto anteriormentese pone de manifiesto que los alcaides, caudillos y cadíes de Vera y su distrito, como representantes del monarca granadino, gozaron de la autoridad y el poder al que se refiere al-Bunnāhī (Cuellas Marqués, 2005: 18 ár. / 108 tr) cuando dice que «entre los

(21) Arcas Campoy (2005), «Habraen Aben Yaçid», pp. 260-264, ofrece varios datos sobre este cadí y sus funciones a partir del testimonio de su hijo, Gonzalo Yaçid. 
musulmanes todo el que asume el poder $(h u k m)$, sea emir, cadí o encargado de la policía (șāhib $a l$-šurța) goza de autoridad». Además de estos cargos de máxima autoridad (alcaides y cadíes), también destacaron otras personas por ejercer funciones de menor categoría, pero importantes y necesarias, en las gestiones de gobierno, defensa, administración y justicia Se trata de un amplio y variado grupo integrado por alguaciles, almojarifes, adalides, alfaqueques, caballeros, jueces delegados, escribanos o alfaquíes. También hay que tener en cuenta a otras personas, socialmente influyentes y respetadas por su prestigio y estatus económico, cuya consideración de hombres prinçipales consta en las declaraciones de varios los testigos.

Un ejemplo del poder y rango del alcaide de Vera se ve reflejado en el episodio de la entrada de Boabdil (Muhammad XI, 887-888/1482-1483 y 892-897/1487-1492) en 1485, proveniente de Lorca, en su jurisdicción territorial por el paso fronterizo de Fuente la Higuera, lugar al que dicha autoridad acudió junto con otras personas destacadas para recibir al monarca y conducirlo a la capital veratense ${ }^{(22)}$ donde, con toda seguridad, sería objeto de los honores y agasajos correspondientes a su dignidad. Así consta en los testimonios de Alonso Arrea (PV, 1518, 62r) y Juan Rael (PV, 1518, 90v-91r), lo que contribuye a dar crédito a los episodios relacionados con la huida de Boabdil a Castilla y su paso por Lorca en el viaje de regreso al territorio nazarí. Juan Rael dice al respecto:

El Rey Chico moro que se desçía Muley Baudali estava en Castilla puede aver ziertos años que no se acuerda y vino de Lorca y otras partes a la dicha fuente La Higuera y que salió el alcayde moro de Vera y otros muchos moros con él y este testigo con ellos y vinieron a la dich a fuente donde hallaron a el dicho rey moro y a los cavalleros que dicho tiene con el benían y que los estavan esperando en la dicha fuente por partimiento y límites de los dichos términos de Lorca y Vera y allí resçivieron al rrey y lo traxeron a Vera y vido que desde la dicha fuente se bolvieron los dichos xpi(sti)anos que con el dicho rrey hasta alli avían venido.

No parece haber lugar a dudas sobre el poder y rango social de quienes ostentaron cargos de autoridad y de quienes gozaron de consideración y respeto por su prestigio personal o familiar. Pero ¿qué se sabe de su capacidad económica y de sus bienes? Realmente no contamos con información concreta sobre esta cuestión, pero partiendo de esta realidad y teniendo en cuenta la gradación de categorías de los cargos, funciones y trabajos de los habitantes más destacados de la frontera oriental nazarí, se abre la posibilidad de articular una hipótesis sobre algunos aspectos relacionados con sus capacidades económicas. Resulta oportuno mencionar aquí el apartado de la Suma de los principales mandamientos y devedamientos de la ley e la çunna de Içe de Gebir(23) dedicado a los doce grados por los que el mundo se rige y gobierna porque, al corresponderse grosso modo algunos de ellos -gobernadores y justiçias, entre otros descendientes del estado y grado de alhalifa, caudillo y ciudadano- con las escalas de autoridad y rango de los cadíes, alcaides, caudillos y hombres principales ${ }^{(24)}$, podría servir de orientación para tratar de valorar e interpretar algunos aspectos del poder económico real de estos personajes a partir de la información contenida en las fuentes consultadas, ciertamente escasa en datos concretos pero de gran utilidad para abordar esta cuestión.

Así pues, no resultaría muy arriesgado suponer que los alcaides, cadíes y caudillos de la zona fronteriza del este del reino de Granada gozaron de una posición economía desahogada, que

(22) Arié (1992), El reino nasrí de Granada, p. 90 y también Jiménez Alcázar (1994), Lorca: ciudad y término (1994), pp. 276-277, y Huércal y Overa (1996), p. 35, mencionan este episodio de Boabdil.

(23) Içe de Gebir (1853), Suma, pp. 412-416. Hay evidentes coincidencias del orden de categorías del texto de Içe de Gebir y con el de Villena (2007), Los doce trabajos de Hércules, pp. 152-154.

(24) El testigo Juan de Narvaez (PV, 1518, 52r) alude a los tres estamentos más relevantes: caudillo, cadís y hombres prinçipales moros. 
derivaría de las asignaciones oficiales correspondientes a su rango y función y, en muchos casos, de sus bienes personales, ni tampoco lo sería mantener la misma suposición en el caso de los hombres prinçipales, denominados así por los testigos, que encajan perfectamente en el grado de ciudadano, según la descripción de Içe de $\mathrm{Gebir}^{(25)}$ : Bajo el grado de ciudadanos biben muchos onrrados hombres que no biben de trabajar con sus manos, sino que tienen heredades de que se mantienen; ni tratan, ni son conoçidos de trato, sino de fe y de conçiençia, pagando sus diezmos y azaques y que cumplen con Allah y ganan buena fama.

Llegados a este punto procede ahora centrarse en la interpretación, valoración y posible deducción de algunos aspectos concretos relativos a la economía de las personas que gozaron de autoridad y prestigio en la taha veratense. El hecho de que varios alcaides tuvieran criados y escuderos a sueldo es un claro signo de su poder económico, hecho del que dan fe varios testigos antes mencionados y a los que se podrían añadir Bartolome de Ayala (PV, 1518, 52v), Françisco El Moçaqui (PV, 1528, 129r) y Garcia Almanzor (PV, 1528, 106r-106v), entre otros. Pero ¿qué se puede conocer respecto a sus propiedades? Para responder a esta pregunta trataremos de contextualizar la información que poseemos del panorama económico de este territorio fronterizo.

Una vez más, los testimonios recogidos en las Probanzas aportan abundantes y valiosos datos sobre diversos aspectos de los recursos naturales de la taha de Vera ${ }^{(26)}$. Figuran nombres de aldeas, pequeños núcleos de población y alusiones al paisaje rural en general ${ }^{(27)}$-montes, acuíferos, vegetación, pastos, tierras, ramblas, animales, etc. - y también a la explotación de dichos recursos, entre los que destacan la obtención de cal, la apicultura, la caza (perdices y conejos con hurones), la ganadería y la agricultura. De dos de estos recursos generadores de economía, el ganado y la tierra, es de suponer que procederían principalmente los bienes y propiedades rurales de las personas más importantes de la zona.

En la documentación consultada son relativamente abundantes los datos sobre los ganados, especialmente los foráneos (de Baza, Caniles, Guadix y otros lugares), sin embargo, no constan referencias específicas sobre rebaños pertenecientes a alcaides, cadíes y otros hombres influyentes de Vera. A pesar de ello, teniendo en cuenta la holgada situación económica que se les supone, parece probable que algunos de ellos fueran dueños de ganados, principalmente ovejuno y caprino.

En cuanto a las propiedades rurales, tampoco se encuentran referencias concretas ni sobre su aprovechamiento ni sobre sus dueños, por lo que es necesario, de nuevo, fundamentar en datos documentados de carácter general algunas deduciones probables. En primer lugar hay que tener en cuenta los rasgos que caracterizaban al agro veratense, rasgos que estaban determinados por factores climáticos, orográficos, sociales, económicos y también políticos, éstos últimos fundamentalmente por su condición de tierra limítrofe. Ya un siglo antes Ibn al-Jaṭîb (2016: 29 ár./49 tr.) se refería a Vera como frontera extrema y lugar de rebato, en que la remuneración de sus defensores es incalculable. Ésta es una villa acechada por el enemigo [constantemente], al punto de que sus habitantes temen que se les tiendan emboscadas.

Partiendo de la complejidad y variedad de los factores determinantes del medio rural de la taha de Vera hay que señalar que, aunque el buen aprovechamiento de los escasos recursos hídricos permitía la actividad agrícola en pequeñas vegas ${ }^{(28)}$, dominaba la agricultura de secano que, siempre a la espera de lluvias beneficiosas y oportunas, estaba dedicada casi exclusivamente a la

(25) Içe de Gebir (1853)), Suma, p. 114. También se aprecia esta similitud con el grado de çibdadano descrito por Villena (2007), Los doce trabajos de Hércules, p. 153.

(26) Hay que tener en cuenta no sólo las características orográficas y climáticas sino también los condicionantes de la proximidad de una frontera con constantes enfrentamientos bélicos en esta última etapa nazarí. El panorama es bastante similar al descrito por Malpica Cuello (2013), «Organización del territorio», pp. 1141.

(27) Sobre el mundo rural andalusí, remito a Trillo San José (2004), Agua, tierra y hombres en al-Andalus.

(28) Jiménez Alcázar (1996), Huércal y Overa, p. 38, indica que la ciudad de Vera tenía una pequeña vega. 
producción cerealística - pan y paniço y otras semillas que se sembraban-cuyos diezmos ${ }^{(29)}$ eran recogidos por todo el territorio por los almojarifes y llevados a las autoridades veratenses. También de las características climatológicas y del cultivo de cereales de la zona se hace eco Ibn al-Jaṭib (2016: 29 ár./49 tr.) cuando, en su relato sobre Vera, refiere que es una dehesa de camellos y un campo de cebada que, gracias a la lluvia, cada grano produce siete espigas, pues sus lomas blanquean con paja, y sus mieses, si la estación [del año] las llama, no desconfian, y responden favorablemente a la exhortación : "Dad lo debido [a los pobres] el día de la cosecha». Y descansamos allí un día [entero], en que el tiempo despertaba de su embriaguez y se reponía de su exceso de agua. "Y se dijeron: "Haz lo que quieras, tierra, pero traga tu agua"». Y apareció el sol como una gran señora, disculpándose por su ausencia, al haberse aprovechado en un descuido del censor ${ }^{(30)}$

Las fuentes consultadas no proporcionan datos concretos respecto a las propiedades de fincas de regadío o de secano, pero las referencias documentadas en otros lugares del reino nazarí, unidas a la información general aportada por los testigos del pleito sobre el medio rural, permiten al menos esbozar deducciones lógicas y extrapolables a las características del territorio de Vera. Así pues tomando como referencia las fincas ubicadas en la vega de Granada, pertenecientes al patrimonio (mustajlaș) del soberano y a terratenientes de clase alta (jașsa) entre los que figuran alcaides y juristas, como en el caso del lugar de Alitaje, pago perteneciente a Pinos-Puente, Granada (Rodríguez Gómez 2016: 37-70), entre otros ejemplos conocidos, resulta lógico pensar que las personas que ejercieron cargos de autoridad en Vera pudieran ser dueños de tierras. Asimismo, no hay duda de que otras personas que gozaron de prestigio y desahogada economía se encontrarían en la nómina de propietarios pues, como hombres prinçipales, sin duda serían dueños de heredades y fincas ${ }^{(31)}$ en las que, sin duda, trabajarían aparceros dentro del marco legal de los diferentes tipos de contratos agrícolas, principalmente el denominado muzāra $a^{\varsigma} a^{(32)}$ para el cultivo de cereales, legumbres y otros granos en tierra de secano. Entre los testigos del pleito figuran muchos labradores que, probablemente, relizarían las labores agrícolas en las propiedades de estos hombres.

La conquista de Vera y su territorio en 1488 generó una serie de cambios políticos, sociales, religiosos y económicos en los que se vieron inmersos sus habitantes, dejando atrás su condición de súbditos del reino nazarí para pasar a la de mudéjares del reino de Castilla y más tarde a la de cristianos nuevos, a raíz de la Pragmática de Conversión Forzosa de 1502, Estos cristianos nuevos, convertidos unos en la etapa mudéjar ${ }^{(33)}$ y obligados otros por la citada Pragmática, aparecen en varios documentos referentes a impuestos, tierras, ganado, bienes, delitos, etc. A pesar del considerable nivel de pobreza de la población de la zona en los últimos años del siglo $\mathrm{XV}$ y en la primera mitad de la siguiente centuria, varios cristianos nuevos gozaron de una

(29) Camarero Castellano (2008), «El azaque de las cosechas en el íslam», pp. 77-121, expone la visión de los juristas malikíes sobre el azaque de las cosechas.

(30) La información aportada por Ibn al-Jațīb en su relato presenta ciertas dificultades de interpretación fuera del contexto estilístico de la obra. El dato que mayor duda crea es la alusión a la existencia de una dehesa de camellos (masrahat al-ba $\bar{\imath}$ r) cerca de Vera, como reconoce el propio editor y traductor de la obra, Fernando Velázquez Basanta (p. 49, nota 139). Entre otras interpretaciones también cabe la posibilidad de que Ibn alJațīb hubiera extrapolado, como recurso literario, la imagen de las dehesas de camellos en el mundo árabe en general al campo de Huércal, habitual zona de pastos y tránsito de ganado, principalmente ovino y caprino.

(31) De nuevo resulta oportuno remitir a las mencionadas similitudes de la categoría de hombres principales de Vera con el grado de ciudadanos mencionados por Içe de Gebir, Suma, p. 414.

(32) Camarero Castellano (2002), «El contrato de aparcería llamado muzāra`a», pp. 181-198, ofrece un análisis de la teoría y práctica de este tipo de contrato documentado en las principales fuentes jurídicas del madhab malikí.

(33) Del Cerro Bex (1980), «Un padrón de los mudéjares» pp. 57-87, ofrece la edición y estudio del Libro de los derechos ordinario de las villas y lugares de Vera (1511), que contiene un padrón fiscal de mudéjares realizado en 1495. En el documento aparecen los nombres de la población mudéjar de Huércal, Antas, Cabrera, Bédar, Overa, Serena y Teresa. Sin duda, algunos de ellos se convirtieron al cristianismo. 
posición económica desahogada de la que dan fe algunos documentos de partición e inventarios de bienes y cartas de dote.

Entre ellos destacan dos personajes de Huércal. El primero es Pedro de Alloza Alaçarin ${ }^{(34)}$, alguacil de Huércal y testigo del pleito, llamado a declarar por la parte de Lorca en los años 1511, 1512, 1517 y 1528. Según el testigo Francisco Albeteri (PL, 1511, 3v), ya ostentaba este cargo cinco o seis años antes de la fecha de su declaración porque indica que entró a sembrar pan en el canpo de Huercal e que alli le aviso un pariente suyo que no senbrasse alli que les prendarían por mandado del conçexo de Lorca e que este testigo luego se salio de allí y que vido que yban tras el Pedro de Alloça e otro que vibe en Huercal e que son de Lorca fasta llegar a un lomo que es ençima del Almarxalexo, aguas vertientes a Çurgena.

Pedro de Alloza, alguacil vitalicio de Huércal, gozaba de una buena posición económica a tenor de la dote e inventario de bienes inmuebles declarados con motivo de su matrimonio en segundas nupcias con Leonor de Alamin. Entre sus bienes inmuebles constan más de cuarenta tahúllas entre tierras de secano y de regadío, con casas, huertas y balsas, todo ello ubicado en diferentes lugares del campo de Huércal y del valle del Almanzora. Además era dueño de bueyes, vacas y treinta reses de cabrito, machos e henbras.

El segundo, Adrián de Huércal, también llamado Adrián Leonés ${ }^{(35)}$, fue alcalde de la villa de Huércal y junto con el mencionado Pedro de Alloza intervino en la defensa de un tal Alonso Adrián, al parecer su hijo, que había sido apresado por la justicia veratense. Su buena posición económica queda reflejada en la partición de bienes, efectuada tras su muerte, entre su mujer, Leonor de Portil, y sus cinco hijos. Entre sus bienes, propios y mejorados por su matrimonio, que ascendían a unos 40.000 maravedíes, constan varias tahúllas y fanegas de tierra en las que se incluyen una casa, oliveras, morales, higueras y colmenas, además de turnos de molino, de almazara y de agua para el riego.

Tanto en la relación de las tierras de Pedro de Alloza como en las de Adrián de Huércal aprecen detallados la ubicación y el nombre de los colidantes.

\section{Consideraciones finales}

Del análisis y estudio de los datos contenidos en las fuentes documentales de este trabajo sobre varios aspectos referentes al rango, poder y economía de las autoridades y de otras personas influyentes de la taha veratense -una microhistoria contextualizada en los últimos tiempos del reino nazarí de Granada- se desprenden las siguientes consideraciones:

a) El gobierno y defensa era responsabilidad de los alcaides y caudillos, nombrados por el monarca granadino. Eran las autoridades de mayor rango y poder de las que dependían otros cargos de menor categoría (alguaciles, almojarifes, adalides, etc.). El alcaide de Vera tenía competencias militares, administrativas y también judiciales en materia penal.

b) Los cadíes, como representantes del soberano en la administración de la justicia, también gozaron de poder y prestigio. Nombrados por el soberano nazarí a través del cadí supremo de Granada, tenían su sede judicial en Vera y su autoridad abarcaba todas las aldeas y villas de su jurisdicción, si bien los testigos de la parte de Lorca defendían que cada población tenía su propio cadí. Las competencias de los cadíes podían ser ordinarias y extraordinarias y con ellos colaboraban otros funcionarios de menor rango.

c) En cuanto a la economía y bienes de los mencionados cargos de máxima autoridad y categoría y de otras personas que gozaban del respeto y consideración social, hay que señalar la

(34) Sobre Pedro de Alloza, véase Jiménez Alcázar (1996), Huércal y Overa, pp. 65-72 y el anexo del documento de su inventario, pp. 135-137; y Arcas Campoy (1999), "Bienes dotales de un alguacil de Huércal, pp. 4151.

(35) Sobre este personaje y sus propiedades, véase Arcas Campoy (2010), «Partición de bienes del morisco Adrián de Huércal», pp. 3-20. 
práctica inexistencia de información al respecto. A pesar de ello, algunos datos concretos, como los referidos a criados y escuderos a sueldo de los alcaides y otros de tipo general sobre el panorama económico de este territorio constituyen una base en la que se puede sustentar la hipótesis de que las autoridades y otros hombres prinçipales de Vera fueron dueños de ganado (ovejuno y caprino) y de tierras de secano y regadío. Hipótesis que se ve reforzada por referencias documentadas en la Vega de Granada y que son extrapolables grosso modo a las características de este territorio fronterizo.

d) Por último cabe destacar el considerable nivel económico de varios cristianos nuevos según se aprecia en algunos documentos legales del siglo XVI. Son muy representativos los casos de Pedro de Alloza y Adrián Leonés, ambos propietarios de un buen número de fincas se secano y de regadío, además de casas, balsas, colmenas, ganado y otros bienes.

\section{Referencias bibliográficas}

ABAD MERINO, Mercedes (2003), «Exeas y alfaqueques: aproximación a la figura del intérprete de árabe en el periodo fronterizo (ss. XIII-XV)», Homenaje al profesor Estanisao Ramón Trives, I, Murcia, pp. 35-50.

ABAD MERINO, Mercedes (2005-2006), «Intérpretes latentes y patentes en el periodo morisco (1501-1568). Del medio oral al medio escrito», Miscelánea Medieval Murciana, $\mathrm{n}^{0}$ 29-30, pp. 9-26.

ABAD MERIno, Mercedes y JimÉnez AlCÁZAR, Juan Francisco (2001), «Item si sabe...: el morisco en los pleitos civiles castellanos», Carlos V. Los moriscos y el Islam, Sociedad Estatal para la conmemoración de los Centenarios de Felipe II y Carlos V / Universidad de Alicante, Madrid, pp. 27-38.

ARIÉ, Rachel (1992), El reino nașrí de Granada (1232-1492), Mapfre, Madrid, pp. 117-188.

ARCAS CAMPOY, María (1992), «Noticias sobre el cadiazgo en los últimos años del reino nazarí: la frontera entre Murcia y Granada», Revista del Centro de Estudios Históricos de Granada y su Reino, 2a época, 6, pp. 203-210.

ARCAS CAMPOY, María (1999), «Cadíes y alcaides de la frontera oriental nazarí (s. XV)», alQanțara, $\mathrm{n}^{\circ}$ 20, fasc. 2, pp. 487-501.

ARCAS CAMPOY, María (1999), «Bienes dotales de un alguacil de Huércal (1519)», Estudios Árabes dedicados a D. Luis Seco de Lucena (En el XXV aniversario de su muerte), AlMudun 3, Granada, pp. 41-51.

ARCAS CAMPOY, María (2005) «Habraen Aben Yaçid, cadí de Vera en los últimos años del reino nazarí», Boletín de la Asociación Española de Orientalistas, $\mathrm{n}^{\circ}$ 41, pp. 255-266.

ARCAS CAMPOY, María (2006) «Sur l'autorité (sultān) dans la administatión de la Justice : le juge, le gouvernant et le juriste », Authority, privacy and public order in Islam, Orientalia Lovaniensia Analecta, no 148, pp. 281-293.

ARCAS CAMPOY, María (2010), «Partición de bienes del morisco Adrián de Huércal (año 1536)», Miscelánea de Estudios Árabes y Hebráicos, Sección Árabe-Islam, nº 59, pp. 320.

ARCAS CAMPOY, María (2014), «Sobre algunas funciones extraordinarias asumidas por el cadí de Vera (siglo XV)», Estudios de Frontera 9. Economía, derecho y sociedad en la frontera. Homenaje a Emilio Molina López. Alcalá la Real, pp. 67-76.

ARCAS CAMPOY, María (2015), «Documentos legales y oficiales de la frontera nordeste del reino de Granada (siglo XV)», Anaquel de Estudios Árabes, n 26, pp. 7-17.

ARCAS CAMPOY, María (2019), «Vera, capital fronteriza del levante del reino nazarí (siglo XV). Una visita retrospectiva», La tierra de Vera. Nuevas contribuciones sobre la historia de un territorio de frontera, Almería, Universidad de Almería, pp. 115-135. 
CALERo SeCAll, $\mathrm{M}^{\mathrm{a}}$ Isabel (2000), «La justicia, cadíes y otros magistrados», José $\mathrm{M}^{\mathrm{a}}$ Jover (dir.) y $\mathrm{M}^{\mathrm{a}}$ Jesús Viguera (coord.), El reino nazarí de Granada (1232-1492), en Historia de España de Menéndez Pidal, VIII-3, pp. 365-427.

CAMARERO CASTEllano, Inmaculada (2002), «El contrato de aparcería llamado muzāra ${ }^{\varsigma} a$, según los juristas malikíes de al-Andalus», Boletín de la Asociación Española de Orientalistas, $\mathrm{n}^{\circ}$ 38, pp. 181-198.

CAMARERO CASTELlano, Inmaculada (2008), «El azaque de las cosechas en el íslam», Ciencias de la nauraleza en al-Andalus. Textos y estudios, VIII, Escuela de Estudios Árabes/Consejo Superior de Investigaciones Científicas, Granada, pp. 77-121.

CARA BARRIONUEVO, Lorenzo y ORTIZ SOLER, Domingo (2019), «Aproximación al conocimiento de la Vera medieval», La tierra de Vera. Nuevas contribuciones sobre la historia de un territorio de frontera, Almería, Universidad de Almería, pp. 71-114.

CERro BeX, Victoriano del (1980), «Un padrón de los mudéjares de la "tierra” de Vera en 1495», Chronica Nova, no 11, pp. 57-87.

CORRIENTE, Federico (1999), Diccionario de Arabismos y voces afines en iberorromance. Madrid, Ed. Gredos.

CUellas MARQUÉS, Arsenio (ob. 1987) (2005), Al-marqaba al-`ulyà de al-Nubāhī (La atalaya suprema sobre el cadiazgo y el muftiazgo. Edición y traducción parciales, con introducción y notas. Celia del Moral (ed.), Al-Mudun, 6, Granada.

EPAlZA, Mikel de (1992), Los moriscos antes y después de la expulsión, Madrid, Mapfre,

EsPinAR Moreno, Manuel y Grima CERVANTES, Juan (1988), «Estudios de algunas cartas de los reyes nazaríes dirigidas a los habitantes de Huércal (1409-1488)», Revista del Centro de Estudios Históricos de Granada y su Reino, no 2 (2 época), pp. 39-57.

EsPinAR Moreno, Manuel y Grima CERVANTES, Juan (1993), «Un personaje almeriense en las crónicas musulmanas y cristianas. El infante Cidi Yahya Alnayar (¿1435?-1506): su papel en la guerra de Granada», Almería y el reino de Granada (s. XX-XVI) (Compendio de Estudios), Almería, pp. 89-124.

ESPINAR Moreno, Manuel y Grima CERVANTES, Juan (1993), «Testamento y muerte de Don Pedro de Granada», Almería y el reino de Granada (s. XX-XVI) (Compendio de Estudios), Almería, pp. 125-149.

FONTENLA BALLESTA, Salvador (1992), «Nueve cédulas reales de los últimos sultanes nazaríes (Primera parte)», Boletín de la Asociación Española de Orientalistas, nº 28, pp. 195-212.

FONTENLA BALLESTA, Salvador (1993), «Nueve cédulas reales de los últimos sultanes nazaríes» (Segunda parte), Boletín de la Asociación Española de Orientalistas, nº 29, pp. 17-30.

GARCÍA ANTÓN, José (1987), «Cautiverios, canjes y rescates en la frontera entre Lorca y Vera en los últimos tiempos nazaríes», Homenaje al profesor D. Juan Torres Fontes, Academia Alfonso X el Sabio, Murcia, pp. 547-559,

IBN AL-JAṬīB (2016), Jațrat al-ṭayf fì rihllat al-šitā $\bar{r}^{\text {w }}$ wa-l-ṣayf. Visión de la amada ideal en una gira inverniza y estival. Edición, traducción y estudio de Fernando Velázquez Basanta, Fundación Ibn Tufayl de Estudio Árabes, Textos y Estudios, 8, Almería.

IÇE DE GEBIR (1853), Suma de los principales mandamientos y devedamientos de la ley y çunna (1462), pp. 247-421, en Tratados de legislación musulmana publicados por Pascual de Gayangos y editados por la Real Academia de la Historia, Madrid.

JiMÉNEZ AlCÁZAR, Juan Francisco (1994), El libro del repartimiento de Vera, Vera.

JIMÉNEZ AlCÁZAR, Juan Francisco (1994), Lorca: ciudad y término (ss. XIII-XVI), Murcia.

JIMÉNEZ AlCÁZAR, Juan Francisco (1996), Huércal y Overa: de enclaves nazaries a villas cristianas (1244-1571), Huércal-Overa.

LuQue de Haro, Víctor Antonio y CAPARrós Perales, Manuel (2019) (eds), La tierra de Vera. Nuevas contribuciones sobre la historia de un territorio de frontera, Almería. 
MALPiCA Cuello, Antonio (2013), «Organización del territorio y estructuras económicas en la frontera nororiental del reino de Granada», Sal, Agricultura y Ganadería. La formación de los paisajes en la Edad Media, Granada, pp. 11-41.

MARTínEZ AlmiRA, Magdalena, (2003), «A propósito del rescate de cautivos conforme a las fuentes musulmanas de época nasrí», Anuario de Historia del Derecho Español, ${ }^{\circ} 73$, pp. 457- 496.

RoDRíGUEZ GóMEZ, María Dolores ((2016), «Emires, linajes y colaboradores: el traspaso de la tierra de la Vega de Granada (Alitaje, siglo XV)», De la alquería a la aljama, Madrid, pp. 37-70.

Trillo SAn José, Carmen (2004), Agua, tierra y hombres en al-Andalus. La dimensión agrícola del mundo nazarí, Granada.

VigueRA Molíns, Ma Jesús (2000), «El soberano, visires y secretarios», José Ma Jover (dir.) y Ma Jesús Viguera (coord.), El reino nazarí de Granada (1232-1492), en Historia de España de Menéndez Pidal, VIII-3, pp. 317-363.

ViLlenA, Enrique de (2007), Los doce trabajos de Hércules (Zamora, por Antón de Centenera, 1483), Estudios de Pedro Cátedra y Paolo Cherchi, Universidad de Cantabria, Santander. 